\title{
Impact of glucose levels on expression of hypha-associated secreted aspartyl proteinases in Candida albicans
}

\author{
Leh-Miauh Buu ${ }^{3}$ and Yee-Chun Chen ${ }^{1,2^{*}}$
}

\begin{abstract}
Background: Ten secreted aspartyl proteinase (Sap) genes were identified in Candida albicans. The products of SAP genes are considered to be virulent factors of C. albicans that participated in causing mucocutaneous and systemic candidiasis in humans. Depending on environmental conditions, C. albicans may stay in yeast-form or convert into invasive hypha-form, and these issues may affect the expression of SAP genes. In this study we explored the component(s) of culture media that may affect the expression of hypha-associated SAP genes.
\end{abstract}

Results: We demonstrate that glucose levels modulate both the hyphae development and the expression strength of hypha-associated SAP genes (SAP4-6). In contrast to high glucose concentration (2\%), lower glucose level (0.1\%) is more potent to promote hyphae development and to promptly elicit the expression of hypha-associated Sap proteins during yeast-to-hypha transition of C. albicans. Both Cph1-mediated MAP kinase cascade and Efg1-mediated CAMP/PKA pathway, although the latter seemed dominant, participate in convey the glucose signaling to regulate the expression of hypha-associated SAP genes and this glucose level effect may perform at very early stage of yeast-to-hypha transition. In addition, when C. albicans was co-cultured with THP-1 human monocytes, the engulfed C. albicans was developing hypha efficiently within $1 \mathrm{hr}$ and the expression of hypha-associated Sap proteins could be detected on the distal surface of hyphae.

Conclusion: We propose that the glucose level of bloodstream (approximately $0.1 \%$ ) may be facilitated for stimulation of C. albicans to develop invasive hypha-form and to elicit promptly production of high-level hypha-associated Sap proteins.

Keywords: Candida albicans, Secreted aspartyl proteinases (Saps), Glucose levels, Candidiasis

\section{Background}

Candida species are ubiquitous human commensal yeasts that reside in mucosae of oral cavity, gastrointestinal tract, female genitalia and skin. Usually they are part of a healthy individual's normal microflora; however, in immunocompromised or disturbed ecosystem of the host, Candida species became pathogenic, causing superficial infection and/or systemic candidiasis [1-3]. The incidence of nosocomial candidiasis was increasing markedly during

\footnotetext{
* Correspondence: yeechunchen@gmail.com

'Division of Infectious Diseases, Department of Internal Medicine, National Taiwan University Hospital, No. 7, Chung-Shan South Road, Taipei 10002, Taiwan

${ }^{2}$ Department of Medicine, National Taiwan University, No. 7, Chung-Shan South Road, Taipei 10002, Taiwan

Full list of author information is available at the end of the article
}

the last decades [4,5]. Candida species became the 4th most common nosocomial bloodstream isolates in United States [5]. In Taiwan, an increasing incidence of candidemia became apparent from 1980 to the end of 1990s, followed by relative stability. Crude mortality rates of patients with candidemia were in the range of 35\% to $60 \%$ [6]. Among the isolates of nosocomial candidiasis, Candida albicans is the predominant cause of invasive candidiasis that accounts for more than $50 \%$ of all cases $[5,6]$.

Several properties of C. albicans are known to contribute to its virulence those basically include the morphological transition from yeast- to hypha-form, adhesion and invasion, and secretion of hydrolytic enzymes [7]. Generally, hyphae development of $C$. albicans can be induced efficiently when they are cultured in liquid media with neutral $\mathrm{pH}$ and requires a temperature of $37^{\circ} \mathrm{C}$ [8]. 
Presently, ten closely related secreted aspartyl proteinase (SAP) genes were identified in C. albicans [9-13]. Studies have established the relation between secreted aspartyl proteinases (Saps) and the pathogenicity of C. albicans [14-17]. The mRNA expression of the SAP4-6 subfamily was first identified in neutral $\mathrm{pH}$ medium with serum to induce hyphae development at $37^{\circ} \mathrm{C}$ [10]. Hence, the expression of SAP4-6 was considered to be associated with the signal cascade of hyphae formation, and this may regulate by several independent but interconnected signal transduction pathways, such as CAMP/PKA pathway and MAP kinase cascade [18,19]. Moreover, hypha-associated SAP4-6 has been investigated as the potent virulent factors in mouse model of systemic candidiasis [20,21].

Phagocytes and neutrophils constitute major obstacles to the establishment of the systemic candidiasis [7,22-24]. Sap4-6 proteins are first detected in C. albicans within macrophages [25]. In such situation, serum is unlikely contributing for expression of SAP4-6 and the intracellular regulated factors remained unknown [25]. The transcriptional response of $C$. albicans upon internalization by macrophages showed that Candida cells underwent gluconeogenesis in the early phase to overcome the starvation [26-28]. Epidemiologic studies have shown that nothing per os and parenteral hyperalimentation are risk factors of healthcare-associated candidemia [29]. Population-based active surveillance also revealed that higher incidence of candidemia in diabetic patients [30]. In our previous study, we tried to examine the expression of hypha-associated $S A P \mathrm{~S}$ at protein level. Referring to other studies, we pre-cultured the C. albicans in the yeast form at $25^{\circ} \mathrm{C}$ for $48 \mathrm{hr}$, and then subcultured the yeast form $C$. albicans in Modified Lee's medium containing $0.2 \% \mathrm{BSA}$ and incubated at $37^{\circ} \mathrm{C}$ to induce yeast-to-hypha transition. After $8 \mathrm{hr}$ of filamentous growth, a little of secreted Sap 5 protein began to be detected; however, the significant amount of Sap5 and trace of Sap4/6 proteins was detected after $24 \mathrm{hr}$ of hyphae induction [31]. This elicited a query that how hypha-associated Sap proteins could be the potent virulent factors if they did not express promptly during the invasive process of hyphae development and need such a long period to induce their expression.

In this study, we tried to explore the component(s) of culture media that may modulate the expression of hypha-associated Sap proteins. We cultured C. albicans strains in several commonly used hypha-inducing media for a period at $37^{\circ} \mathrm{C}$, and then inspected the hyphae development and detected the production of hyphaassociated Sap proteins. By adjustment the composition of media and evaluation the effect on the filamentous growth and Saps expression, we demonstrated that glucose levels should be an important environmental factor for induction of hyphae development and modulation the expression level of hypha-associated SAP genes during yeast-to-hypha transition and during C. albicans was engulfed by phagocytes. We proposed that glucose level of bloodstream (approximately 0.1\%) may be facilitated to provoke the invasive properties of C. albicans.

\section{Methods}

\section{Strains, media, and morphological analysis}

The $C$. albicans strains used in this study were listed in Table 1 [20,32-35]. Media used in induction of hyphae formation and expression of hypha-associated genes included: Modified Lee's medium [36,37] with $0.1 \%$ or $2 \%$ glucose, spider medium [38], YP medium (1\% yeast extract, $2 \%$ peptone) with indicated glucose concentration. All media contained $40 \mathrm{mg}$ of uridine/ $\mathrm{L}$ to minimize the URA3 effect [39]. For hyphae induction, C. albicans strains were freshly cultured on YPD (YP medium with $2 \%$ glucose) plate at $25^{\circ} \mathrm{C}$ or $30^{\circ} \mathrm{C}$ for overnight and cells were inoculated into various liquid media with initial density of $\mathrm{OD}_{600}=1 / \mathrm{ml}$, then incubated at $37^{\circ} \mathrm{C}$ for indicated times with gentle shaking. For observation the morphology of C. albicans, cells were loaded on polylysine coated glass slides and fixed by $3.7 \%$ formaldehyde. For each condition, 30-view of microscopy was photographed and the morphological proportion of $C$. albicans cells was calculated. The morphological analysis was defined according to the following criteria: yeast form, single cell or cell with bud; germ tube, filament $</=$ one mother cell length; short hypha, filament $</=$ two mother cell length; long hypha, filament $>$ two mother cell length. Experiments were repeated three times.

\section{Co-culture of $C$. albicans with THP-1 human monocytes}

The THP-1 human monocytic cell line [40] was maintained in RPMI1640 with $10 \%$ fetal bovine serum (RPMI-FBS) at $37^{\circ} \mathrm{C}$ in a humidified chamber containing $5 \% \mathrm{CO}_{2}$. For co-culture, THP-1 cells were cultured in the $10-\mathrm{cm}$ dishes for 2 days, then removed medium and suspended cells in fresh RPMI-FBS by gentle pipetting and incubated at $37^{\circ} \mathrm{C}$ for $10 \mathrm{~min}$ before co-cultured

Table 1 C. albicans strains used in this study

\begin{tabular}{lll}
\hline Strain type and number & Genotype & Reference \\
\hline Clinical isolate SC5314 & URA3/URA3 & {$[32]$} \\
CAF4-2 (parental strain) & ura3::imm434/ura3::imm434 & {$[33]$} \\
sap2 (M12/BH52-1-17) & sap2::hisG/sap2::hisG::URA3::hisG & {$[34]$} \\
sap4 (DSY436) & sap4::hisG/sap4::hisG::URA3::hisG & {$[20]$} \\
sap5 (DSY452) & sap5::.hisG/sap5::hisG::URA3::hisG & {$[20]$} \\
sap6 (DSY346) & sap6::hisG/sap6::hisG::URA3::hisG & {$[20]$} \\
efg1 & efg1::hisG/efg1:: hisG::URA3::hisG & {$[35]$} \\
cph1 & cph1::hisG/cph1::.hisG::URA3::hisG & {$[35]$} \\
\hline
\end{tabular}


with C. albicans. About $2 \times 10^{6}$ C. albicans cells were co-cultured with $2 \times 10^{5}$ THP- 1 cells in $1.5 \mathrm{ml}$ of RPMIFBS in a $2 \mathrm{ml}$ microcentrifuge tube at $37^{\circ} \mathrm{C}$ incubator for indicated times with gentle rocking [40].

\section{Protein isolation and Western blotting}

Proteins that existed in culture media were precipitated by $10 \%$ TCA (trichloroacetic acid). For investigation on the expression of hypha-associated Sap proteins in $C$. albicans during phagocytosis, C. albicans SC5314 was co-cultured with THP-1 cells. After $1 \mathrm{hr}$ cultivation at $37^{\circ} \mathrm{C}$, co-cultured cells were harvested and suspended in lytic solution (Tris- $\mathrm{HCl}$, pH7.5, $10 \mathrm{mM}$; EDTA $10 \mathrm{mM}$; $\mathrm{NaCl} 50 \mathrm{mM}$; SDS $0.2 \%$ ). Then $\mathrm{ddH}_{2} \mathrm{O}$ was added to thoroughly lyse the THP-1 cells. Candida cells were harvested by low speed centrifugation (1,200 g for $3 \mathrm{~min}$ ) and were washed once by $\mathrm{ddH}_{2} \mathrm{O}$. Then Candida cells were suspended in solution containing $1 \% \beta$-mercaptoethanol and Zymolase. After incubating at $37^{\circ} \mathrm{C}$ for $30 \mathrm{~min}$, the secreted proteins that were released in supernatant were precipitated by $10 \%$ TCA. The Western blotting procedure and preparation of polyclonal anti-Sap6 antibody have been described [31].

\section{Immunofluorescence of hypha-associated Sap proteins}

C. albicans and THP-1 cells were co-cultured at $37^{\circ} \mathrm{C}$ for $30 \mathrm{~min}$ (for phagocytosis), then cells were harvested by low speed centrifugation and re-suspended in RPMI-FBS and incubated at $37^{\circ} \mathrm{C}$ for further $30 \mathrm{~min}$ (hyphae development of THP-1-engulfed Candida cells). Co-cultured cells were harvested and suspended in PBS and loaded on poly-lysine coated cover glasses. The coated cells were fixed by $3.7 \%$ of formaldehyde in PBS for $15 \mathrm{~min}$ and were permeated by $0.2 \%$ TritonX100 for 3 min. After blocking (PBS $+5 \%$ skim milk), cells were incubated with anti-Sap6 antibody (1:500-dilution) for $90 \mathrm{~min}$. The detailed procedure has been described [41].

\section{RNA preparation and reverse transcription-polymerase} chain reaction

C. albicans SC5314 $\left(\mathrm{OD}_{600}=10\right)$ was inoculated into YPD, RPMI-FBS, or co-cultured with THP-1 cells in RPMI-FBS, respectively, then incubated at $25^{\circ} \mathrm{C}$ for YPD and at $37^{\circ} \mathrm{C}$ for later two media. Candida cells were harvested after 30 min cultivation and total RNA was isolated by hot acid phenol method [42]. Before reverse transcription, $2 \mu \mathrm{g}$ of total RNA was treated by DNaseI (Invitrogen). The SuperScriptIII (Invitrogen) and oligo-(dT) ${ }_{12-18}$ were used to generate the cDNA. The expression of hypha-associated SAP genes was identified by PCR amplification using specific primers that were listed in Table 2 [19].
Table 2 Primers used for reverse transcription-PCR analysis in this study

\begin{tabular}{lll}
\hline Primer & Sequence $\left(\mathbf{5}^{\prime}\right.$ to $\mathbf{3}^{\prime}$ ) & Reference \\
\hline SAP4-1 & TGCCGATGGTTCTTGCAC & This study \\
SAP4-2 & AACTTGAGCCATGGAGATCTTTC & This study \\
SAP5-1 & GCGGCGAAGCTACCGAGTTTG & This study \\
SAP5-2 & TACCACTAGTGTAATATGTTTGGA & This study \\
SAP6a & AAACCAACGAAGCTACCAGAAC & {$[19]$} \\
SAP6b & TAACTTGAGCCATGGAGATTTC & {$[19]$} \\
EFB1a & AGTCATTGAACGATTCTTGGCTG & {$[19]$} \\
EFB1b & TTCTTCAACAGCAGCTTGTAAGTC & {$[19]$} \\
\hline
\end{tabular}

\section{Results}

Expression of Sap5 in hypha-inducing conditions

For explore the factor(s) that may have an effect on the expression of Sap proteins, we firstly examined whether the hypha-associated Sap proteins can be expressed in commonly used hypha-induced media. After several times of pre-test, we incubated C. albicans SC5314 at $37^{\circ} \mathrm{C}$ for $1 \mathrm{hr}$ in different liquid media with initial cell density of $\mathrm{OD}_{600}=1 / \mathrm{ml}$ to induce hyphae development. This culture condition was applied in all of hyphainducing experiments of this study. The expression of hypha-associated Sap4 6 proteins were identified by Western blotting using polyclonal anti-Sap6 antibody which can recognize Sap4 6 proteins [31]. Moreover, the morphology of Candida cells was inspected and calculated. The results demonstrated that about $85 \%$ of Candida cells undertook yeast-to-hypha transition (germ tube + short hypha + long hypha) when cultured in spider medium, and $75 \%$ in YPD medium containing $2 \%$ fetal bovine serum (FBS), and 65\% in YPD medium (Figure 1B). Secreted Sap5 protein, which is the most abundant secreted Sap protein during hyphae development, was only detected in precipitates of spider medium (Figure 1A) that contained mannitol instead of glucose. This result provide a hint that hyphae development of $C$. albicans can be induced efficiently under $37^{\circ} \mathrm{C}$ in almost all commonly used neutral $\mathrm{pH}$ media, but the expression rate and expression level of hyphaassociated Sap proteins may be affected by certain components of culture media. By comparison the media compositions we suspected the glucose level, but not the addition of serum or BSA that was commonly used in many studies, may be an important issue to affect the expression of Sap proteins in the course of yeast-tohypha transition.

\section{Glucose levels modulate Sap5 expression in hypha-inducing} conditions

In order to elucidate the glucose effect on the promptly expression of Sap proteins during hyphae development, 
A

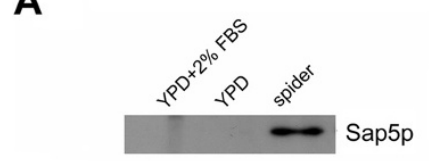

B $_{45}$

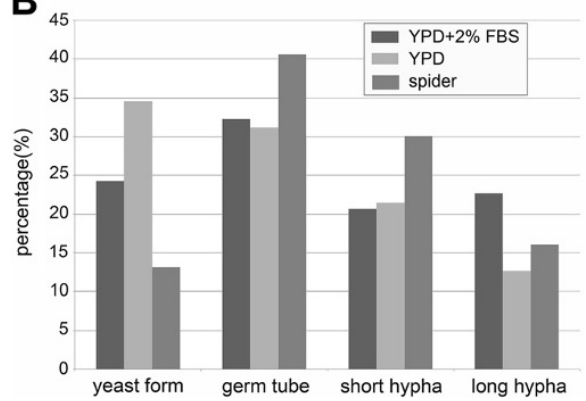

C

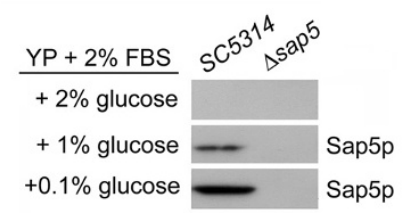

D

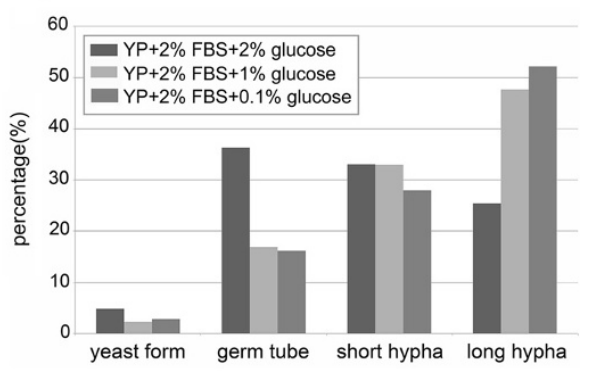

Figure 1 Expression of Sap5 in spider medium and lower glucose level media. C. albicans SC5314 was inoculated into various media with initial density of $\mathrm{OD}_{600}=1 / \mathrm{ml}$. Cells were harvested after cultured at $37^{\circ} \mathrm{C}$ for $1 \mathrm{hr}$. The media components were precipitated by $10 \%$ TCA for Western blot analysis and the cells were fixed by 3.7\% formaldehyde for morphology observation. (A) The secreted Sap5 (Sap5p) was detected in precipitate of spider medium by Western blotting using polyclonal anti-Sap6 antibody which can recognize Sap4 $\sim 6$ proteins. (B) The analysis of morphological proportion of C. albicans SC5314 that was cultured in panel (A) described condition. (C) The Sap5 was rapidly and highly expressed in low glucose concentration (0.1\%) during yeast-to-hypha transition. FBS: fetal bovine serum. (D) The analysis of morphological proportion of C. albicans SC5314 that was cultured in panel (C) described condition.

we cultivated Candida cells in YP medium containing $2 \%$ FBS and adding $2 \%, 1 \%$, or $0.1 \%$ of glucose, respectively, at $37^{\circ} \mathrm{C}$ for $1 \mathrm{hr}$. The results demonstrated that in these culture conditions, more than $95 \%$ of Candida cells underwent yeast-to-hypha transition. Indeed, Candida cells that cultured in $1 \%$ and $0.1 \%$ glucose exhibited similar ratio of yeast-to-hypha transition (Figure 1D), but secreted Sap5 protein was far more abundant in medium containing $0.1 \%$ glucose (Figure $1 C$ ). These results demonstrated that hyphae development of C. albicans can be enhanced by serum supplement, but the glucose levels display a substantial effect on regulation the expression strength of hypha-associated Sap5 protein.

\section{Low glucose level enhances yeast-to-hypha transition and provokes Saps expression}

Above results also demonstrated that high glucose level seems to delay the hyphae expansion of $C$. albicans even though in the serum supplement condition (Figure 1D). We further investigated whether the glucose levels affect the hyphae formation and the expression of hypha-associated Sap proteins. The results showed that without serum, after $1 \mathrm{hr}$ incubation at $37^{\circ} \mathrm{C}$, lower glucose level ( $\mathrm{YP}+0.1 \%$ glucose) could induce hyphae formation more efficiently (Figure 2B), and more of secreted Sap5 was identified in medium under this condition (Figure 2A). Hence, low glucose level facilitates hyphae development and rapidly enhances Sap5 expression during the yeast-to-hypha transition.
Moreover, we incubated C. albicans strains in synthetic Modified Lee's medium containing $2 \%$ or $0.1 \%$ glucose, respectively, and without BSA supplement. After $2 \mathrm{hr}$ cultured at $37^{\circ} \mathrm{C}$, abundant Sap 5 and trace of Sap6 (compared wild type strain with sap-deleted mutants, data not shown) were detected in medium with $0.1 \%$ glucose (Figure $2 \mathrm{C}$ ). Again, this result proved that the glucose level has an effect on modulation the expression level of hypha-associated Sap proteins. Moreover, this result can explain our previous study [31] that $C$. albicans after $12 \mathrm{hr}$ of filamentous growth at $37^{\circ} \mathrm{C}$ in Modified Lee's medium containing 0.2\% BSA and 2\% glucose, the glucose was consumed gradually, more Sap5 and even Sap6 could be detected in lower glucose concentration medium.

\section{Regulation the expression of hypha-associated Sap proteins} in hyphae development with low glucose condition

Efg1 and Cph1 are respective the downstream effector of cAMP/PKA signaling pathway and MAP kinase cascade, and both were shown to regulate the hyphae development and the expression of hypha-associated virulent factors in C. albicans including hypha-associated Sap proteins $[19,43]$. When cultivation of $C$. albicans strains in Modified Lee's medium containing $2 \%$ glucose at $37^{\circ} \mathrm{C}$ for $4 \mathrm{hr}$, the expression of Sap proteins was undetected in efg1-null or cph1-null mutants and only trace of Sap5 protein could be detected in wild type SC5314 strain. However, when C. albicans strains were cultured in $0.1 \%$ glucose at $37^{\circ} \mathrm{C}$ for $4 \mathrm{hr}$, abundant Sap5 protein and little 
A

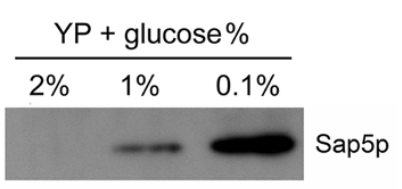

C

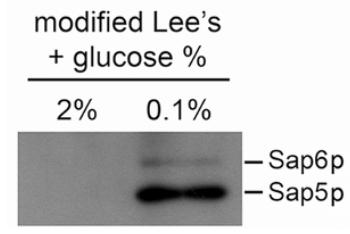

E

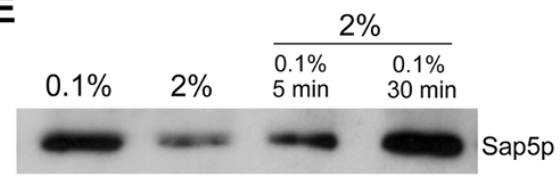

B

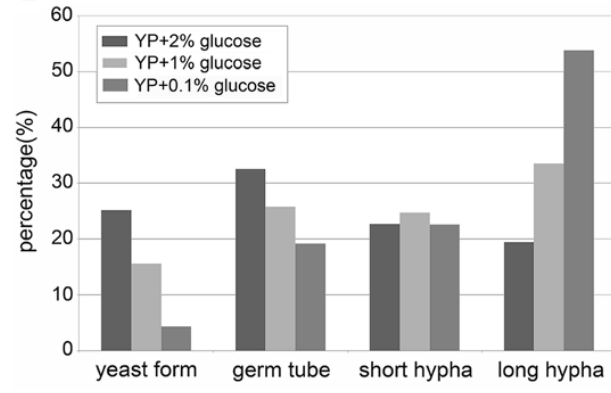

D

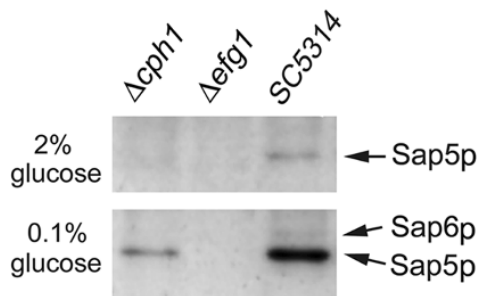

Figure 2 Low glucose level enhances hyphae formation and provokes the expression of hypha-associated Sap proteins. (A) C. albicans SC5314 was cultured at $37^{\circ} \mathrm{C}$ for $1 \mathrm{hr}$ in YP medium containing different concentration of glucose. More of secreted Sap5 was detected in medium with lower glucose concentration (0.1\%). (B) The analysis of morphological proportion of C. albicans SC5314 that was cultured in panel (A) described condition. (C) Abundant Sap5 and trace of Sap6 proteins were detected in Modified Lee's medium containing $0.1 \%$ glucose after $2 \mathrm{hr}$ incubation at $37^{\circ} \mathrm{C}$. (D) The expression of Sap5 and Sap6 was impaired in cph1-null strain and was abolished in efg1-null strain. (E) Exploration the high glucose level represses Sap5 expression during yeast-to-hypha transition. C. albicans SC5314 was cultured in YP medium containing $0.1 \%$ glucose at $37^{\circ} \mathrm{C}$. Glucose level was re-added up to $2 \%$ at indicated incubation times and then still cultured at $37^{\circ} \mathrm{C}$; the total incubation period was 90 min. Secreted Sap5 was detected by Western blot analysis.

of Sap6 protein were produced by wild type strain SC5314 and trace of secreted Sap5 protein could be detected in medium of cph1-null mutant (Figure 2D). In fact in liquid media, the cph1-null strain appeared delayed hyphae development, and the filamentous growth of efg1-null mutant was abolished (data not shown). Hence, we deduced that both cAMP/PKA signaling pathway and the MAP kinase cascade can convey the glucose signaling that may sequential or cross-connect to affect the yeast-to-hypha transition and modulate the expression of hypha-associated Sap proteins, especially the Efg1-mediated cAMP/PKA pathway dominates the major effect.

Besides, we also investigated the suppressive effect of high glucose level on Sap5 expression. We cultured $C$. albicans cells in YP medium containing $0.1 \%$ glucose at $37^{\circ} \mathrm{C}$ and glucose concentration was re-added up to $2 \%$ at several incubation time points respectively, and then still cultured at $37^{\circ} \mathrm{C}$; the total incubation period was 90 min. The Western blotting revealed (Figure 2E) the Sap5 expression can be repressed when glucose concentration was re-added up to $2 \%$ at the time point of $5 \mathrm{~min}$ incubation. However, after $30 \mathrm{~min}$ incubation, the Sap5 expression was not repressed effectively by replenished high glucose concentration. In fact, even as early as readded glucose concentration up to $2 \%$ at $10 \mathrm{~min}$ incubation, the suppressive effect of high glucose level on Sap5 expression was not evident (data not shown). Therefore, the glucose level modulates the expression of hypha-associated SAPs may perform at very early stage during yeast-to-hypha transition of C. albicans.

\section{Expression of hypha-associated Sap proteins during phagocytosis}

We also examined the expression of hypha-associated Sap proteins in co-culture system of THP-1 human monocyte and C. albicans. The composition of THP-1 culture medium (RPMI1640 with 10\% FBS) contained about $0.4 \%$ glucose. Reverse transcription-PCR analysis revealed that the mRNA level of hypha-associated $S A P$ genes $(S A P 4 \sim 6)$ was elevated after 30 min incubation of C. albicans in cell culture medium (RPMI-FBS) at $37^{\circ} \mathrm{C}$ (Figure 3A, compare $\mathrm{Y}$ and $\mathrm{S}$ ). Moreover, the expression of SAP4 $\sim 6$ genes was further enhanced in co-cultured condition (Figure 3A, compare $\mathrm{S}$ and $\mathrm{C}$ ), and this result was proved by Western blotting (Figure 3B). Besides, after $1 \mathrm{hr}$ co-culture at $37^{\circ} \mathrm{C}$, the engulfed C. albicans was developing hyphae efficiently in THP-1 cells, and the immunofluorescence showed that hypha-associated Sap proteins were detected on the distal surface of hyphae (Figure 3C, D). These results demonstrated that $C$. albicans could develop filamentous growth rapidly after 


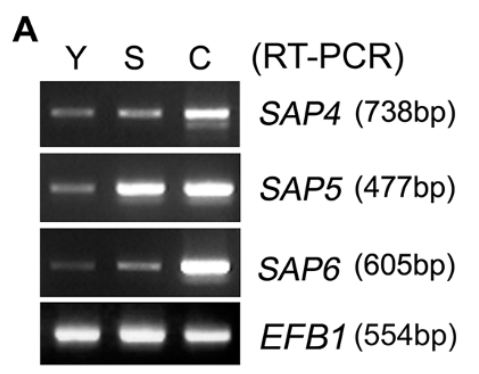

C
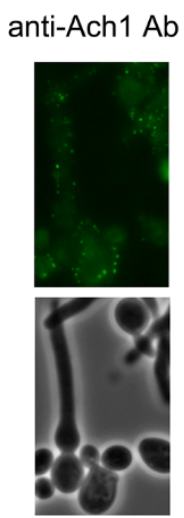

B

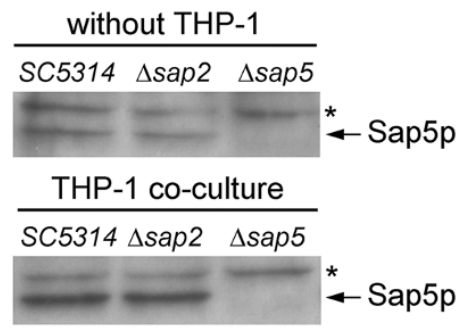

D

C. albicans SC5314/THP-1 monocyte

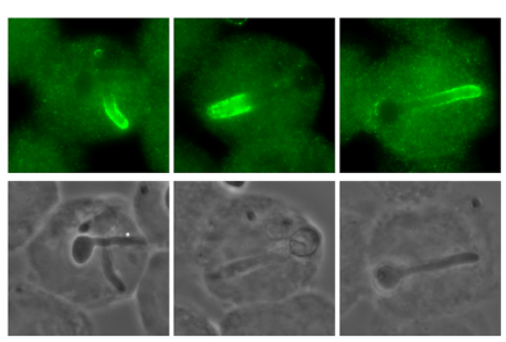

Figure 3 Expression of hypha-associated Sap proteins during phagocytosis. (A) C. albicans SC5314 was cultured in YPD medium at $30^{\circ} \mathrm{C}$ to maintain yeast form, in RPMI-FBS (which contained 10\% FBS and $0.4 \%$ glucose) medium at $37^{\circ} \mathrm{C}$ to generate hypha-form, and co-cultured C. albicans with THP-1 human monocytes in RPMI-FBS medium at $37^{\circ} \mathrm{C}$. The expression of hypha-associated SAP genes was identified by reverse transcription-PCR analysis using gene specific primers. Y: YPD, S: RPMI-FBS, C: co-culture. EFB1 gene is an internal control. (B) Detection the secreted Sap5 protein in C. albicans and THP-1 co-culture condition by Western blot analysis. The * is a non-specific signal. Protein samples of the upper panel and the lower panel were manipulated simultaneously. (C) Detection the secreted Sap proteins on hyphae surfaces of $C$. albicans by immunofluorescence staining using polyclonal anti-Sap6 antibody as primary antibody. The polyclonal anti-Ach1 antibody is a negative control. (D) Detection the expression of secreted hypha-associated Sap proteins during phagocytosis by immunofluorescence staining. The majority of fluorescent signals distributed on the distal surface of hyphae.

phagocytosis and considerable amount of hypha-associated Sap proteins would be expressed promptly during this process.

\section{Discussions}

This study manifested that during hyphae development of C. albicans, the expression strength of hyphaassociated Sap proteins can be modulated by glucose levels. Serum is known to be an efficient substance to enhance yeast-to-hypha transition of C. albicans at $37^{\circ} \mathrm{C}$, but it seems not to be the most potent factor to elicit the expression of hypha-associated Sap proteins during hyphae development [44]. Yeasts have been shown to have a refined genetic program that responsible for sensing, acquisition, and utilization of glucose $[45,46]$. In the in vitro environment, glucose depletion can cause invasive growth of S. cerevisiae on solid agar [47]. In addition, filamentous growth of $C$. albicans can be induced effectively on solid minimal medium containing $0.1 \%$ glucose relative to higher glucose levels [48]. In our study of culture conditions, low glucose level $(0.1 \%$ glucose $)$ is more potent to promote hyphae formation and to elicit the expression of SAP5 and SAP6 accompanying with yeast-to-hypha transition of $C$. albicans, and the protein products can be detected after short period ( $\sim \mathrm{hr}$ ) of hyphae induction.

Although glucose is abundant and convenient for utilizing on earth, it is usually a restrictive nutrient within biological systems for commensal and parasitical microorganisms. Therefore, it is reasonable to consider that the natural habitats of $C$. albicans should be glucoselimited. In both S. cerevisiae and C. albicans, three independent but cross-regulated signal transduction pathways have been shown to sense and convey the glucose signaling and eventually to generate a coordinated response [49]. The Hgt4 of C. albicans is presently known as a high-affinity glucose sensor which can respond to glucose levels as low as $0.01 \%$ [50]; certainly, this sensor is considered to be functional when $C$. albicans survived under physiological glucose levels of human host (0.1\%). In addition, activated Gpr1/Gpa2-GTP and activated Ras1GTP may also function as glucose-sensing system that to modulate cAMP/PKA pathway [49,51]. However, abundant 
glucose may elicit the glucose repression pathway that enable to repress genes required for the usage of nonfermentable carbon sources, genes in the process of the cAMP/PKA pathway, and genes encoded the highaffinity Hgt proteins which required in glucose-limited condition [49]. Accordingly, we assumed that the glucose level in physiological condition of human is sufficient to activate the glucose utilization network in C. albicans but not high enough to provoke the glucose repression response. A recent study indicated that glucose levels in the bloodstream $(0.05-0.1 \%)$ have a crucial effect upon the gene regulation of C. albicans [52]. However, most of researchers cultured $C$. albicans in yeast extract-peptone-dextrose (YPD) or other media, such as synthetic complete medium, usually containing $2 \%$ glucose and provided serum to enhance hyphae development at $37^{\circ} \mathrm{C}$. In these culture conditions, expression of many genes may be repressed by high glucose level and the resulted profiles of gene expression may far different from the state of $C$. albicans in its in vivo habitats. Besides, earlier studies have demonstrated that low glucose concentration $(0.1 \%)$ could provoke the germ-tube formation of $C$. albicans more efficiently than that of high glucose levels [53,54]. Indeed, in our study, expression of Sap5 and Sap6 also could be rapidly induced when cultured C. albicans at $37^{\circ} \mathrm{C}$ in YP (yeast extract-peptone) medium without glucose containing (data not shown). Hence, glucose concentration in culture media should be considered as an important modulation factor when studies the gene expression patterns of C. albicans.

Moreover, our results demonstrated both cAMP/PKA pathway and the MAP kinase cascade in C. albicans are important for regulation the high expression level of hypha-associated Sap proteins that triggered by $0.1 \%$ glucose, especially through the Efg1-mediated cAMP/ PKA pathway. Studies have revealed that some environmental signals, including nitrogen and glucose levels, can be conveyed to both cAMP/PKA and the MAP kinase pathways through regulator Ras1 [8,51]. However, the Efg1 is the dominant effector for hyphae formation when $C$. albicans was cultured in liquid media, and the cAMP/PKA pathway plays major role in initiation of hyphae development under most conditions [8]. Therefore, we suggested that prompt expression of hyphaassociated Sap proteins may depend on efficient initiation of hyphae development by Efg1-mediated cAMP/ PKA pathway and the maintenance of high expression level of hypha-associated Sap proteins may require the coordination of Cph1-mediated MAP kinase cascade.

Several host defense proteins in the mucosa surface, such as salivary lactoferrin, $\alpha$-macroglobulin (proteinase inhibitor), secretory immunoglobulin A, and enzymes of the respiratory burst of macrophages can be hydrolysed by Sap proteins [55]. These macrophages are predominantly located beneath the intestine epithelial layer within the lamina propria [56-58]. Based on our in vitro studies, we inferred that during in vivo infection, once C. albicans transferred from intestinal or other mucosa surfaces to invade deep tissues where temperature near $37^{\circ} \mathrm{C}$, and $/$ or intravascular invasion facing glucose concentration around $100 \mathrm{mg} / \mathrm{dL}(0.1 \%)$ [48]; both signals and serum would efficiently induce hyphae formation and elicit expression of hypha-associated Sap proteins in C. albicans. In addition, the study of transcriptional response has revealed that upon internalization by macrophages, the C. albicans underwent gluconeogenesis in the early phase to overcome the starvation situation [27]. Besides, inside the phagocytes, the phagosome-containing microorganisms would fuse with cellular lysosomes to form the microbicidal phagolysosomes; however, many pathogenic microbes are able to endure in phagocytes that may render by activating the potent virulent factors of microbes during phagocytosis [25]. In our study, we demonstrated that the rapidly enhanced expression of hypha-associated SAP genes was one of the downstream responses which were modulated by factors activating by the stress and starvation signals after $C$. albicans was engulfed in phagocytes.

\section{Conclusions}

This study demonstrated that adjusting the glucose levels in culture media to imitate the physiological condition of human $(0.1 \%$ glucose $)$ is efficient to enhance the expression level of hypha-associated SAP genes in $C$. albicans, and this condition may also regulate the expression of other virulent factors during hyphae development of $C$. albicans. In addition, this study provides biological evidence for the clinical findings that nothing per os, parenteral hyperalimentation and poor controlled diabetes, which may influence the in vivo glucose levels, are risk factors of candidiasis.

\section{Abbreviations \\ SAP: Secreted aspartyl proteinase; BSA: Bovine serum albumin; FBS: Fetal bovine serum; TCA: Trichloroacetic acid; dL: Deciliter.}

\section{Competing interests}

The authors declare that they have no competing interests.

\section{Authors' contributions}

LMB designed and manipulated the experiments and participated in manuscript writing. YCC discussed the experimental design and results with LMB and participated in manuscript writing. Both authors read and approved the final manuscript.

\section{Acknowledgments}

The authors are grateful to Drs. Bernhard Hube, Dominique Sanglard, Gerald R. Fink, and William A. Fonzi for providing the strains of C. albicans, and thankful to Dr. Fang-Jen S. Lee for providing antibodies. We thank the facilities support at the 6th Core Laboratory, National Taiwan University Hospital. This work was supported by the National Science Council, Taiwan (NSC 902314-B-002-304, NSC 91-2314-B-002-130). 


\section{Author details}

'Division of Infectious Diseases, Department of Internal Medicine, National Taiwan University Hospital, No. 7, Chung-Shan South Road, Taipei 10002, Taiwan. ${ }^{2}$ Department of Medicine, National Taiwan University, No. 7 Chung-Shan South Road, Taipei 10002, Taiwan. ${ }^{3}$ Department of Biotechnology, National Kaohsiung Normal University, No. 62, Shenzhong Rd. Yanchao District, Kaohsiung City 82444, Taiwan.

Received: 12 September 2013 Accepted: 11 March 2014

Published: 15 March 2014

\section{References}

1. Chen Y-C, Chang S-C, Tai H-M, Hsueh P-R, Luh K-T: Molecular epidemiology of Candida colonizing critically ill patients in intensive care untis. J Formos Med Assoc 2001, 100:791-797.

2. Segal E: Candida, still number one- what do we know and where are we going from there? Mycoses 2005, 48:3-11.

3. Pfaller MA, Diekema DJ: Epidemiology of invasive candidiasis: a persistent public health problem. Clin Microbiol Rev 2007, 20:133-163.

4. Chen Y-C, Chang S-C, Sun C-C, Yang L-S, Hsieh W-C, Luh K-T: Secular trends in the epidemiology of nosocomial fungal infection at a teaching hospital in Taiwan, 1981-1993. Infect Control Hosp Epidemiol 1997, 18:369-375.

5. Edmond MB, Wallace SE, McClish DK, Pfaller MA, Jones RN, Wenzel RP: Nosocomial bloodstream infections in United States hospitals: a three-year analysis. Clin Infect Dis 1999, 29:239-244.

6. Ruan S-Y, Hsueh P-R: Invasive Candidiasis: an overview from Taiwan. J Formos Med Assoc 2009, 108:443-451.

7. Calderone RA, Fonzi WA: Virulence factors of Candida albicans. Trends Microbiol 2001, 9:327-335.

8. Sudbery PE: Growth of Candida albicans hyphae. Nature Rev Microbiol 2011, 9:737-748.

9. White TC, Miyasaki SH, Agabian N: Three distinct secreted aspartyl proteinases in Candida albicans. J Bacteriol 1993, 175:6126-6133.

10. Hube B, Monod M, Schofield DA, Brown AJ, Gow NAR: Expression of seven members of the gene family encoding secretory aspartyl proteinases in Candida albicans. Mol Microbiol 1994, 14:87-99.

11. Monod M, Togni G, Hube B, Sanglard D: Multiplicity of genes encoding secreted aspartic proteinases in Candida species. Mol Microbiol 1994 13:357-368.

12. Monod M, Hube B, Hess D, Sanglard D: Differential regulation of SAP8 and SAP9, which encode two new members of the secreted aspartic proteinase family in Candida albicans. Microbiology 1998, 144:2731-2737.

13. Albrecht A, Felk A, Pichova I, Naglik JR, Schaller M, de Groot P, MacCallum D, Odds FC, Schafer W, Klis F, Monod M, Hube B: Glycosylphosphatidylinositol-anchored proteases of Candida albicans target proteins necessary for both cellular processes and host-pathogen interactions. J Biol Chem 2006, 281:688-694.

14. Kwon-Chung KJ, Lehman D, Good C, Magee PT: Genetic evidence for role of extracellular proteinase in virulence of Candida albicans. Infect Immun 1985, 49:571-575

15. Cassone A, De Bernardis F, Mondello F, Ceddia T, Agatensi L: Evidence for a correlation between proteinase secretion and vulvovaginal candidosis. $J$ Infect Dis 1987, 156:777-783.

16. De Bernardis F, Arancia S, Morelli L, Hube B, Sanglard D, Schafer W, Cassone $A$ : Evidence that members of the secretory aspartyl proteinase gene family, in particular SAP2, are virulence factors for Candida vaginitis. J Infect Dis 1999, 179:201-208.

17. Naglik J, Albrecht A, Bader O, Hube B: Candida albicans proteinases and host/pathogen interactions. Cell Microbiol 2004, 6:915-926.

18. Schweizer A, Rupp S, Taylor BN, Rollinghoff M, Schroppel K: The TEA/ATTS transcription factor CaTec1p regulates hyphal development and virulence in Candida albicans. Mol Microbiol 2000, 38:435-445.

19. Felk A, Kretschmar M, Albrecht A, Schaller M, Beinhauer S, Nichterlein T, Sanglard D, Korting HC, Schafer W, Hube B: Candida albicans hyphal formation and the expression of the Efg1-regulated proteinases Sap4 to Sap6 are required for the invasion of parenchymal organs. Infect Immun 2002, 70:3689-3700.

20. Sanglard D, Hube B, Monod M, Odds FC, Gow NAR: A triple deletion of the secreted aspartyl proteinase genes SAP4, SAP5, and SAP6 of Candida albicans causes attenuated virulence. Infect Immun 1997, 65:3539-3546.
21. Kretschmar M, Hube B, Bertsch T, Sanglard D, Merker R, Schroder M, Hof H, Nichterlein T: Germ tubes and proteinase activity contribute to virulence of Candida albicans in murine peritonitis. Infect Immun 1999, 67:6637-42.

22. Mansour MK, Levitz SM: Interactions of fungi with phagocytes. Curr Opin Microbiol 2002, 5:359-365.

23. Romani L: Immunity to fungal infections. Nature Rev Immunol 2004, 4:1-23.

24. Netea MG, Brown GD, Kullberg BJ, Gow NAR: An integrated model of the recognition of Candida albicans by the innate immune system. Nature Rev Microbiol 2008, 6:67-78

25. Borg-von Zepelin M, Beggah S, Boggian K, Sanglard D, Monod M: The expression of the secreted aspartyl proteinases Sap4 to Sap6 from Candida albicans in murine macrophages. Mol Microbiol 1998, 28:543-554.

26. Rubin-Bejerano I, Fraser I, Grisafi P, Fink GR: Phagocytosis by neutrophils induces an amino acid deprivation response in Saccharomyces cerevisiae and Candida albicans. Proc Natl Acad Sci USA 2003, 100:11007-11012.

27. Lorenz MC, Bender JA, Fink GR: Transcriptional response of Candida albicans upon internalization by macrophages. Eukaryotic Cell 2004, 3:1076-1087.

28. Fradin C, De Groot P, MacCallum D, Schaller M, Klis F, Odds FC, Hube B: Granulocytes govern the transcriptional response, morphology and proliferation of Candida albicans in human blood. Mol Microbiol 2005, 56:397-415

29. León C, Ruiz-Santana S, Saavedra P, Almirante B, Nolla-Salas J, Alvarez-Lerma F, Garnacho-Montero J, León MA, EPCAN Study Group: A bedside scoring system ("Candida score") for early antifungal treatment in nonneuropenic critically ill patients with Candida colonization. Crit Car Med 2006, 34:730-7.

30. Kao AS, Brandt ME, Pruitt WR, Conn LA, Perkins BA, Stephens DS, Baughman WS Reingold AL, Rothrock GA, Pfaller MA, Pinner RW, Hajjeh RA: The epidemiology of candidemia in two United States cities: results of a population-based active surveillance. Clin Infect Dis 1999, 29:1164-1170.

31. Chen Y-C, Wu C-C, Chung W-L, Lee F-J S: Differential secretion of Sap4-6 proteins in Candida albicans during hyphae formation. Microbiology 2002, 148:3743-3754.

32. Gillum AM, Tsay EY, Kirsch DR: Isolation of the Candida albicans gene for orotidine- 5'-phosphate decarboxylase by complementation of S. cerevisiae ura3 and E. coli pyrF mutations. Mol Gen Genet 1984, 198:179-182.

33. Fonzi WA, Irwin MY: Isogenic strain construction and gene mapping in Candida albicans. Genetics 1993, 134:717-728

34. Hube B, Sanglard D, Odds FC, Hess D, Monod M, Schafer W, Brown AJ, Gow NAR: Disruption of each of the secreted aspartyl proteinase genes SAP1, SAP2, and SAP3 of Candida albicans attenuates virulence. Infect Immun 1997, 65:3529-3538.

35. Lo HJ, Kohler JR, DiDomenico B, Loebenberg D, Cacciapuoti A, Fink GR: Nonfilamentous Candida albicans mutants are avirulent. Cell 1997 90:939-949.

36. Lee KL, Buckley HR, Campbell CC: An amino acid liquid synthetic medium for the development of mycelial and yeast forms of Candida albicans. Sabouraudia 1975, 13:148-153.

37. Morrow B, Srikantha T, Soll DR: Transcription of the gene for a pepsinogen, $P E P 1$, is regulated by white-opaque switching in Candida albicans. Mol Cell Biol 1992, 12:2997-3005.

38. Navarro-Garcia F, Alonso-Monge R, Rico H, Pla J, Santendreu R, Nombela C A role for the MAP kinase gene MKC1 in cell wall construction and morphological transitions in Candida albicans. Microbiology 1998, 144:411-424.

39. Brand A, MacCallum DM, Brown AJP, Gow NAR, Odds FC: Ectopic expression of URA3 can influence the virulence phenotypes and proteome of Candida albicans but can be overcome by targeted reintegration of URA3 at the RPS10 locus. Eukaryot. Cell 2004, 3:900-909.

40. Barker KS, Liu T, Rogers PD: Coculture of THP-1 human mononuclear cells with Candida albicans results in pronounced changes in host gene expression. J Infect Dis 2005, 192:901-912.

41. Buu L-M, Chen Y-C, Lee F-J S: Functional characterization of acetyl-CoA hydrolase, Ach1p, in Saccharomyces cerevisiae. J Biol Chem 2003, 278:17203-9.

42. Collart MA, Oliviero S: Supplement Unit 13.12. Preparation of yeast RNA In Current Protocols in Molecular Biology. Edited by Ausubel FM, Brent R, Kingston RE, Moore DD, Seidman JG, Smith JA, Struhl K. New York: John Wiley \& Sons, Inc; 1993:13.12.1-5. 
43. Staib P, Kretschmar M, Nichterlein T, Hof H, Morschhäuser J: Transcriptional Regulators Cph1p and Efg1p Mediate Activation of the Candida albicans Virulence Gene SAP5 during Infection. Infect Immun 2002, 70:921-927.

44. Staib P, Binder A, Kretschmar M, Nichterlein T, Schroppel K, Morschhauser J: Tec1p-independent activation of a hypha-associated Candida albicans virulence gene during infection. Infect Immun 2004, 72:2386-2389.

45. Fan J, Chaturvedi V, Shen S-H: Identification and phylogenetic analysis of a glucose transporter gene family from the human pathogenic yeast Candida albicans. J Mol Evol 2002, 55:336-346.

46. Santangelo GM: Glucose signaling in Saccharomyces cerevisiae. Microbiol Mol Biol Rev 2006, 70:253-282.

47. Cullen PJ Jr, Sprague GF: Glucose depletion causes haploid invasive growth in yeast. Proc Natl Acad Sci USA 2000, 97:13619-13624.

48. Maidan MM, Thevelein JM, Van Dijck P: Carbon source induced yeast-tohypha transition in Candida albicans is dependent on the presence of amino acids and on the G-protein-coupled receptor Gpr1. Biochem Socie Transac 2005, 33:291-293.

49. Sabina J, Brown V: Glucose sensing network in Candida albicans: a sweet spot for fungal morphogenesis. Eukaryot Cell 2009, 8:1314-1320.

50. Brown V, Sexton JA, Johnston M: A glucose sensor in Candida albicans. Eukaryot Cell 2006, 5:1726-1737.

51. Biswas S, Van Dijck, Datta PA: Environmental sensing and signal transduction pathways regulating morphopathogenic determinants of Candida albicans. Microbiol Mol Biol Rev 2007, 71:348-376.

52. Rodaki A, Bohovych IM, Enjalbert B, Young T, Odds FC, Gow NAR, Brown AJP: Glucose promotes stress resistance in the fungal pathogen Candida albicans. Mol Biol Cell 2009, 20:4845-4855.

53. Hrmova M, Drobnica L: Induction of mycelial type of development in Candida albicans by low glucose concentration. Mycopathologia 1981, 76:83-96.

54. Vidotto V, Accattatis G, Zhang Q, Campanini G, Aoki S: Glucose influence on germ tube production in Candida albicans. Mycopathologia 1996, 133:143-147.

55. Hube B, Naglik J: Candida albicans proteinases: resolving the mystery of a gene family. Microbiology 2001, 147:1997-2005.

56. Hume DA, Allan W, Hogan PG, Doe WF: Immunohistochemical characterizations of macrophages in human liver and gastrointestinal tract: expression of CD4, HLA-DR, OKM1 and the mature macrophage marker 25 F9 in normal and diseased tissue. J Leukocyte Biol 1987, 42:474-484.

57. Nagashima R, Maeda K, Imai Y, Takahashi T: Lamina propria macrophages in the human gastrointestinal mucosa: their distribution, immunohistological phenotype, and function. J Histochem Cytochem 1996, 44:721-731.

58. Pavli P, Maxwell L, Van De Pol E, Doe WF: Distribution of human colonic dendritic cells and macrophages. Clin Exp Immunol 1996, 104:124-132.

doi:10.1186/1423-0127-21-22

Cite this article as: Buu and Chen: Impact of glucose levels on expression of hypha-associated secreted aspartyl proteinases in Candida albicans. Journal of Biomedical Science 2014 21:22.

\section{Submit your next manuscript to BioMed Central and take full advantage of:}

- Convenient online submission

- Thorough peer review

- No space constraints or color figure charges

- Immediate publication on acceptance

- Inclusion in PubMed, CAS, Scopus and Google Scholar

- Research which is freely available for redistribution

Submit your manuscript at www.biomedcentral.com/submit 